\title{
Linking depositional environments and diagenetic processes to porosity evolution and destruction in the Arab Formation
}

: reservoirs, Offshore oilfields of Qatar
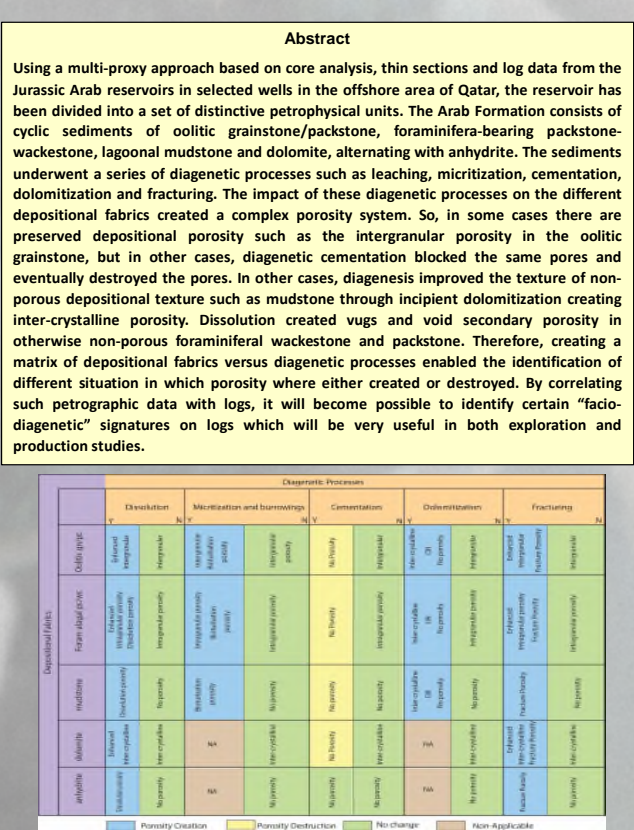

A matrix of the main depositional fabrics of the Arab Formation versus the The main rock types forming the Arab Formation are oolitic-peloidal grainstone-wackestone that formed persistent shoals all over the region, shallow-shelf carbonates formed of limestone and dolomitic limestone containing large benthonic foraminfera with green algae, mudstone with less than $10 \%$ of small dwarfed fossils which are believed to form in saline lagoon or restricted shelves, dolomite which represents a replaced texture some of them are difficult to recognize with beds of anhydrite. The main diagenetic the final deposition of the formation, bioturbation that include micritization and burrows, cementation which was mainly meteoric blocky cement, and fracturing as a result of tectonic activity.

Plotting the two components versus each other led to the creation of a matrix that shows the best combination to create or destroy porosity as well as the cases where the original status is preserved. Clear from the table that diagenesis is creating more porosity than destroying it. This best example of this is the impact of dissolution that elther enhance the intergranular, dissor dissolving the less stable components. Dolomitization and fracturing also

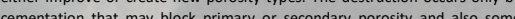
interlocking dolomite that destroy the pores. So in to improve the reservoir characteristics of the formation.

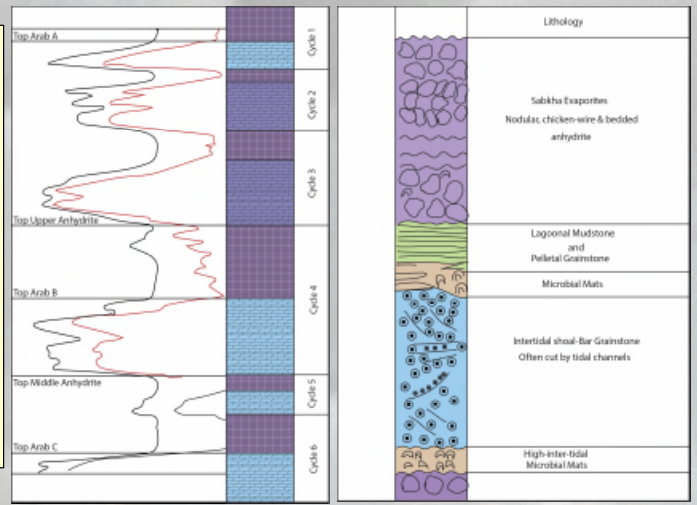

Typical lithologies of the Arab Formation

Depositional cycles of the Arab Formation

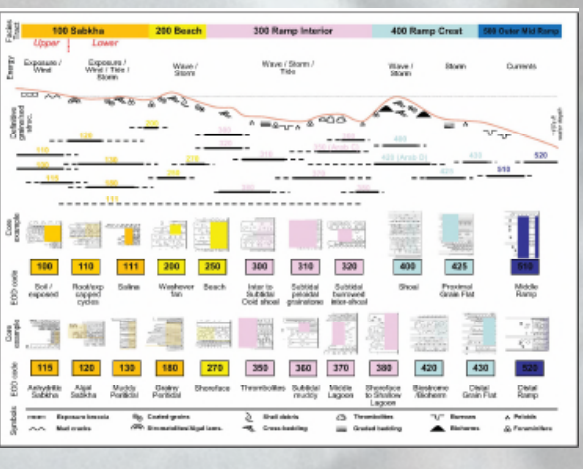

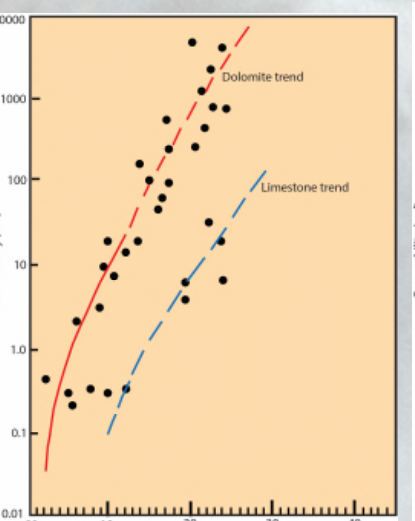

Porosity Destruction
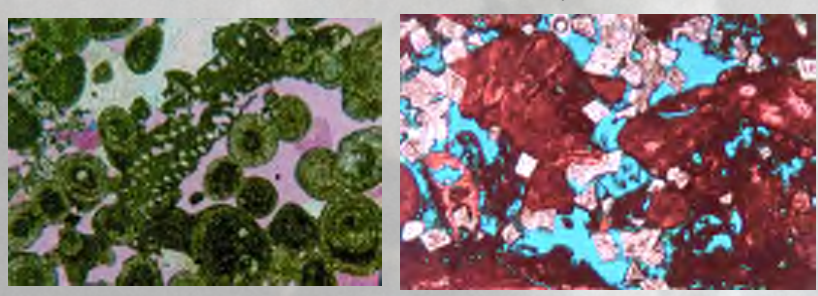

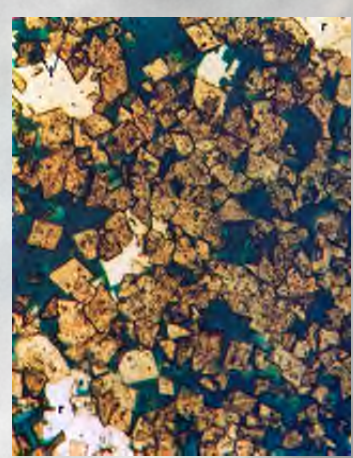

op left: Oolitic grainstone which is a typical reservoir rock of the Arab formation. In usual cases (

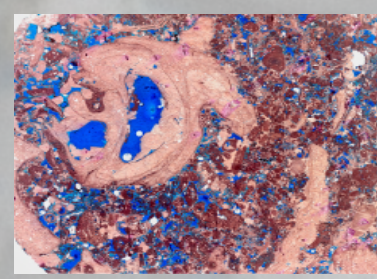

Intragranular porosity in bioclastic packstone

Intragranular porosity in bic

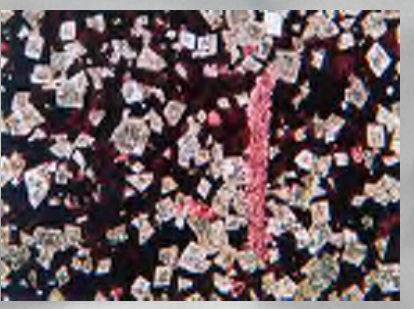

Inter-crystalline porosity created by dolomitization of otherwise impervious mudston

Conclusions
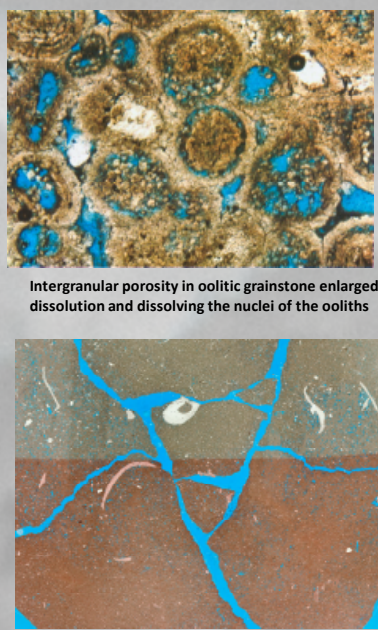

Core piece formed of two contrasting micritic lime mudstone. Usually these rocks have no significant porosity, but fractures are well-developed and can be
porosity and permeability channels at the same time Middle: Peloidal bioclastic grainstone. The blue areas are pores, but large parts of these pores a

op right: Saccharoidal dolomite with well-developed inter-crystallin
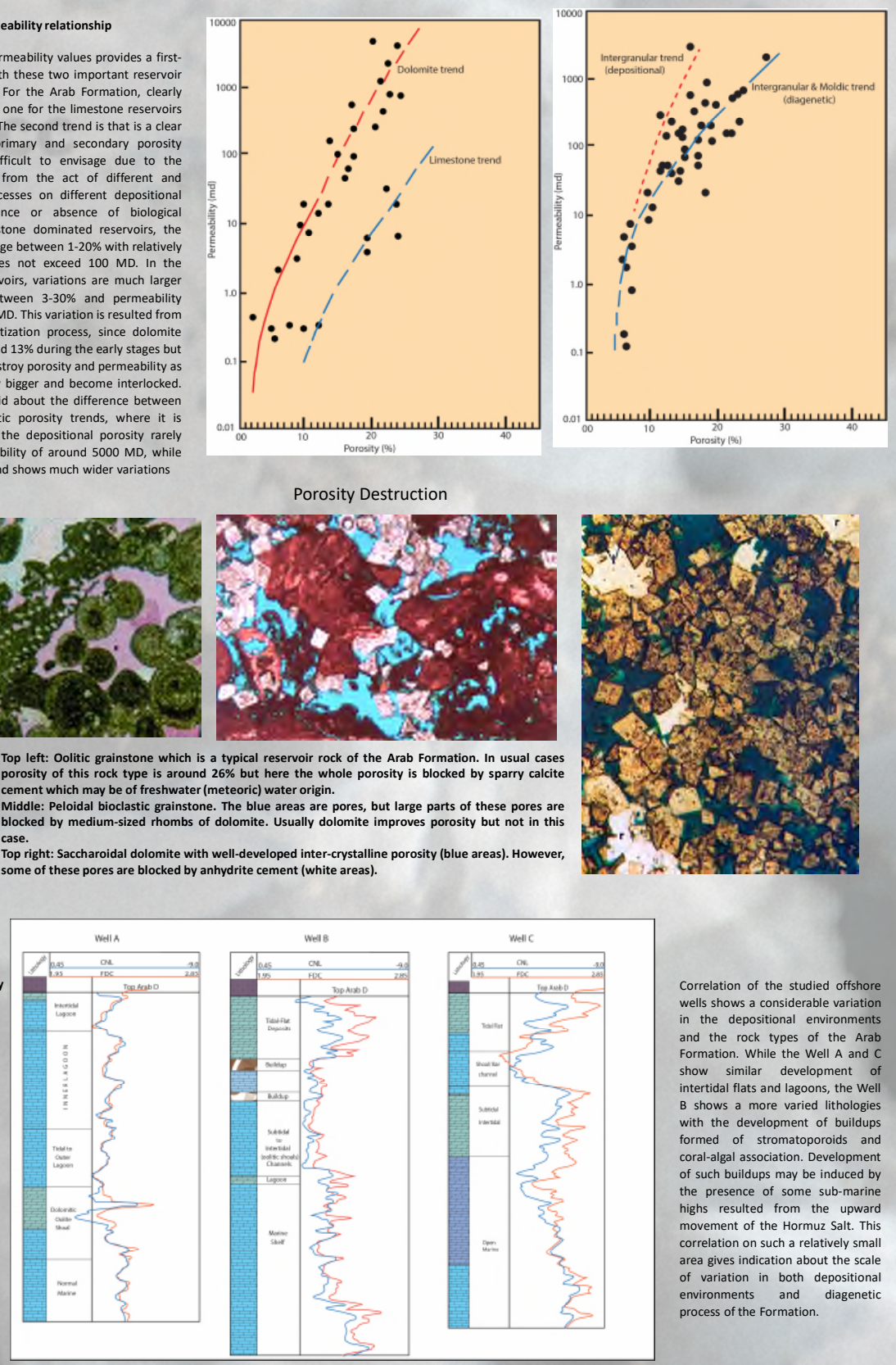

Correlation of the studied offshore wells shows a considerable variation and the rock types of the Arab Formation. While the Well A and C show similar development of intertidal flats and lagoons, the Well B shows a more varied lithologies formed of stromatoporoids and coral-algal association. Development the highs resulted from the upward movement of the Hormuz Salt. This area gives indication about the scale of variation in both depositional environments and diagenetic process of the Formation.

1. The Jurassic Arab Formation reservoirs in the offshore oilfields of Qatar shows a wide variation in the depositional environments in a relatively small area. 2. These rocks were subjected also to varied diagenetic processes that destructed partially or totally the original fabrics of the rocks and created new fabrics. 3. A matrix is developed between the depositional environments and diagenetic processes.

4. It is found that diagenesis was constructive in most of the time creating secondary porosity as it is the cases with bioturbation, dolomitization, and

fracturing and destructive in the case of cementation.

6. These units National Research Fund Grant \# NPRP11S-0109-180241. We are grateful to the Environmental Science Center for production and photographic facilities 